\title{
Elderly patients with very late-onset schizophrenia-like psychosis and early-onset schizophrenia: Cross-sectional and retrospective clinical findings
}

\author{
Caroline Girard $^{1,2}$, Martine Simard ${ }^{1,2^{*}}$ \\ ${ }^{1}$ School of Psychology, Laval University, Quebec City, Canada \\ ${ }^{2}$ Research Centre at Mental Health University Institute of Quebec, Quebec City, Canada \\ Email: ${ }^{*}$ Martine.Simard@psy.ulaval.ca
}

Received 15 June 2012; revised 18 July 2012; accepted 29 July 2012

\begin{abstract}
Objectives: The aim of this study was to characterize the symptoms at onset/past and current symptoms of patients with Very Late-Onset Schizophrenia-Like Psychosis (VLOSLP; first onset of psychotic symptoms at/or after 60 years old) with those of elderly

both VLOSLP and EOS had positive and negative symptoms in the past/at onset of the disease, but they were more severe in EOS than in VLOSLP. However, the positive symptoms of both groups at follow-up of the cohort (current evaluation) responded relatively well to neuroleptics.
\end{abstract} patients diagnosed with schizophrenia before the age of 40 years old (Early-Onset Schizophrenia-EOS) in order to validate the clinical nosology proposed by the International Late-Onset Schizophrenia Group. Methods: This is a between-patient comparison study with retrospective and current data taken from an historical cohort that was conducted from May/2005 to August/2008. Seventeen VLOSLP and 17 EOS were included. Schizophrenia and schizophrenia-like psychotic disorders were initially diagnosed by boardcertified psychiatrists with the Diagnostic and Statistical Manual Criteria at use at onset of the disorders. Patients' symptoms were assessed with the Scale for the Assessment of Positive Symptoms (SAPS) and the Scale for the Assessment of Negative Symptoms (SANS). The general scores on the SAPS/SANS were the primary outcomes. Results: Both groups had hallucinations and delusions at onset of the disease, but the following symptoms were more present and severe in EOS than in VLOSLP: hallucinations ( $p=$ 0.001); assiduity loss $(p<0.001)$; grandiosity $(p=$ $0.001)$; reference $(p<0.001)$ and influence $(p=0.001)$ delusions. VLOSLP had mostly persecutory delusions. At current evaluation (follow-up of cohort), most patients in the two groups presented residual symptoms of anhedonia and apathy, but EOS, presented more symptoms of friendship poverty $(d=1.42$, large effect size) than VLOSLP. The neuroimaging studies (when available) at follow-up demonstrated greater vascular cerebral lesions/vulnerability in VLOSLP than in EOS patients. Conclusion: This study showed that

${ }^{*}$ Corresponding author.
Keywords: Psychosis; Negative Symptoms; Schizophrenia; Very-Late-Onset

\section{INTRODUCTION}

A recent study found that the one-year prevalence of all schizophrenia spectrum disorders in individuals aged 60 years and older was $0.71 \%$ [1]. Clearly, with the aging of population, these late-onset disorders will become a more important health issue [2,3]. Indeed the greatest per-capita expenditures for individuals with schizophrenia were reported among the older beneficiaries [4]. At the beginning of the new millennium, The International Late-Onset Schizophrenia (ILOS) Group attempted to disentangle inconsistencies regarding the diagnostic systems and nomenclature of late-onset schizophrenia/psychosis disorders [5]. Following a Medline literature review and two days of debate, this group achieved consensus on diagnosis and recommended a nosology for these disorders: The diagnosis of late-onset schizophrenia (LOS) for an illness onset after the age of 40 and the diagnosis of very-late-onset schizophrenia-like psychosis (VLOSLP) for an illness onset after the age of 60. The International Late-Onset Schizophrenia Group proposed that early-onset schizophrenia or EOS (onset before the age of 40) and LOS (onset after 40 years old) would be more similar than different in terms of symptoms $[5,6]$ whereas VLOSLP (onset after 60 years old) would present with a lower prevalence of formal thought disorder and affective blunting, and a higher prevalence of visual hallucinations than EOS [5]. This nomenclature may 
have had face validity and clinical utility, but required further investigation in several domains, especially regarding the differential clinical symptomatology with EOS $[5,7]$.

Following the publication of the nomenclature proposed by the ILOS Group, numerous studies were conducted to differentiate the clinical profile between LOS and EOS patients [6,8-17]. However, because the present paper will rather focus on VLOSLP/EOS than on LOS/ EOS, the LOS/EOS differential nomenclature will not be further developed; the interested readers shall consult Pearman and Batra [6] for a recent review on this particular topic.

Studies on VLOSLP alone [18-23], as well as studies comparing the profile of patients with VLOSLP with that of patients with LOS $[14,24,25]$, elderly EOS $[14,24$, 26-29] and healthy controls [30,31] were also realized to better differentially characterize the demographics, clinical symptoms and evolution $[14,20,29]$ of VLOSLP patients.

In terms of positive symptoms, mild paranoid delusions $[14,26]$ mostly persecutory $[18,20,21,24,25]$, auditory $[18,21,25,26]$ and visual hallucinations $[18,21,25]$, as well as all the Scale for the Assessment of Positive Symptoms (SAPS) [32] behavioral disturbances except for psychomotor abnormalities [25] were described in VLOSLP. These symptoms were sometimes as common as in LOS [25]. However, presence of formal thought disorders in VLOSLP generated contradictory results. Some authors reported formal thought disorders in 100\% of French-speaking VLOSLP patients [25], while other authors working mostly on English- and Deutsch-speaking patients reported a low prevalence [18], and a lower risk of formal thought disorder in VLOSLP than in EOS patients [14]. Formal thought disorder was found to be absent in VLOSLP patients in the remaining studies [20, 24].

The presence of negative symptoms was also very controversial $[14,20,21,25]$. In a previous study realized by our team [25], both VLOSLP and LOS patients presented with several negative symptoms as measured by the Scale for the Assessment of Negative Symptoms (SANS) [33]; only apathy was more frequent in LOS than in VLOSLP. However, in most studies, negative symptoms were absent in VLOSLP [14,20] while they were present in EOS and to a lesser extent in LOS [14]. Negative symptoms were not at all or barely mentioned in several studies on VLOSLP [18,21,24,26].

Regarding the evolution of VLOSLP, Mazeh and colleagues [29] reported that the majority of VLOSLP patients did not present cognitive and functional deterioration over a mean follow-up period of 30 months, on the contrary to EOS patients ( $42 \%$ with functional decline and $16 \%$ with cognitive decline). However, the research- ers only administered the Clinical Global Impression (CGI) scale and a telephone interview in which they asked 3 questions to the caregiver in order to assess the cognitive and functional status of the patient. Köhler and colleagues [14] also found that generally, later age of onset was associated with better outcome, although there was a significant gender by age of onset interaction, with men displaying poorer outcome in the EOS/LOS group and women tending to have a worse outcome in the VLOSLP.

Good response to antipsychotics [24,26,34,35], even better than in LOS [24] and elderly EOS patients [24,26], was often registered in VLOSLP patients. VLOSLP individuals, especially inpatients [35], responded well to atypical antipsychotics [20,35], and in particular to amisulpride [34].

In terms of sociodemographics, there was generally a female preponderance in VLOSLP $[1,14,18,20,22,24-26$, 29]. Regarding education, in one instance patients with VLOSLP were described as being more educated than elderly EOS [26] but in another study they were reported to be less educated than LOS [25]. Regarding social abilities, VLOSLP patients were described as having a better premorbid social functioning than elderly EOS, because they had been more married [26] and/or widowed/divorced $[22,25]$ than single. However, other authors found that a majority of VLOSLP patients living in the community were alone [20]. Male patients with VLOSLP might be more socially isolated than women [23].

Interestingly, some studies have shown that ethnicity might play a role on the demographics and symptoms' profiles of VLOSLP [20-23]. Some authors reported that Black Caribbean $[20,21]$ as well as migrant patients with different ethnic origins [22,23] diagnosed with VLOSLP were younger and more likely to be male than their British counterparts. Black Caribbean VLOSLP patients tended to present more with delusions of a "bizarre" or mystical nature and with a somatic or hypochondriacal content than British patients [21].

In summary, studies on VLOSLP patients over the last decade have consistently reported the presence of paranoid delusions and generally less severe positive symptoms than in EOS. However, the presence/absence and severity of negative symptoms remains a controversial issue. Regarding the evolution of VLOSLP, gender might have an impact on the outcome, with VLOSLP women possibly having a poorer prognosis than men; but few studies addressed this question so further research are required. Finally, ethnicity might play a role in demographic characteristics as well as in the clinical profile of VLOSLP patients. As there were very few studies conducted on a French-speaking population with VLOSLP, the differential clinical and sociodemographic profile of 
French-speaking patients with VLOSLP versus that of French-speaking patients with EOS shall be further investigated. Indeed, do VLOSLP patients share the same symptomatology/etiology than EOS, or do they have a neurodegenerative and/or neurovascular substrate to their disorder as it has been suggested by some authors [36$38]$ ?

To address these issues, our team performed a historical cohort study on the cognitive and clinical profile/ evolution of elderly patients with VLOSLP versus those of patients with life-long EOS. The detailed method and cognitive results were presented in a previous report [39]. In summary, although VLOSLP and EOS patients did not meet the diagnostic criteria for dementia at onset of the psychotic disorder, the results showed that the groups presented at follow-up with cognitive deficits in several domains, and $20 \%$ of VLOSLP had developed dementia overtime (after onset of psychotic disorders) compared to $5.9 \%$ of EOS [39].

The objective of the present paper is thus to present the clinical results of this historical cohort study, i.e. to characterize and compare the current (follow-up) and past (at onset of the psychotic disorder) positive and negative symptoms of patients with VLOSLP with those of patients aged 55 years and older who received a diagnosis of EOS. In terms of clinical profile, VLOSLP were hypothesized to present with less severe current (followup) and past positive symptoms than EOS, to present with some negative symptoms, but of less severity than those of EOS patients. In terms of demographics, VLOSLP were hypothesized to be predominantly female, to have a better premorbid social functioning, i.e. to be more married/widowed/divorced than EOS (more single), and to be less educated than EOS, per the findings of a previous study on a French-speaking population by our team [25].

\section{METHODS}

Research design and settings: This was a betweenpatient comparison study made at follow-up, with a retrospective component (onset of the psychotic disorder), following the historical cohort [39]. Patients were recruited in psychiatric/geriatric psychiatry units of five hospitals in the province of Quebec, Canada.

Participants: Seventeen elderly patients presenting for the first time at/or after 60 years old with either schizophrenia, schizophreniform disorder, delusional disorder, non-specific psychotic disorder or paraphrenia (VLOSLP) were compared to 17 patients aged 55 years old and older who had received a diagnosis of schizophrenia before the age of 40 (EOS). Supplementary inclusion criteria for both groups involved: 1) The absence of dementia at onset of the initial psychotic episode (per the medical chart) (onset of historical cohort); and 2) psy- chotic symptoms at onset (of historical cohort) not explained by another psychiatric and/or neurological and/or systemic/medical disorder. The initial diagnoses had to be made by board-certified psychiatrists using the official Diagnostic and Statistical Manual Criteria (DSM) employed at the time.

Ethical considerations: This research was approved by the Ethical Research Committee of all hospitals involved in this study. Written informed consent was obtained from every patient and/or legal substitute by a research assistant not involved in the evaluation. Patients had to: 1) Consent to participate in the evaluations of the study; 2) Allow the investigator to review the medical file or, if not, accept to answer a socio-demographic/medical questionnaire; 3) Allow an investigator to contact a family member/friend (facultative, given that patients presenting with paranoid symptoms might be reluctant to involve family members of friends in the study); 4) Consent to have a summary of his/her results put in his/her personal medical file (facultative). All data were coded/ registered anonymously in the database.

Material: Socio-demographics and medical data were first collected using a standard questionnaire on physical status, medical/family antecedents, current medications (dosages) and past investigations. This information was corroborated by the patient medical records (when consent obtained, see above). A semi-structured interview designed to investigate the current and past psychiatric symptoms was afterwards administered. This interview was based on the Scale for the Assessment of Positive Symptoms (SAPS) [32], and the Scale for the Assessment of Negative Symptoms (SANS) [33]. Each symptom was scored using a Likert scale (from $0=$ absence to 4 = very important) reflecting the severity of each symptom.

Statistical analyses: Descriptive and univariate analyses were performed to compare some socio-demographics and present/past symptom profile of VLOSLP and EOS. Chi-square and Fisher's exact test were conducted to compare categorical variables. Independent ttests were used to compare continuous variables. Analyses were performed using SPSS for Windows version 17. This was an analytical study and thus multiple comparisons were made. An alpha of $p<0.05$ was applied to the socio-demographic (Table 1), medical (Table 2) and primary variables (Table 3) which were the general scores obtained on the SAPS/SANS (see Table 3). Only the variables found significant on these general scores were further analysed to specify the symptoms' typology. A Bonferroni correction was applied to these results in order to avoid the type I error. As a result, an alpha of $p \leq$ 0.001 was determined. In addition, Effect sizes $(d)$ [40], were calculated on all descriptive data of Tables 3-5 with the following interpretation per Cohen [40]: $d=$ 
Table 1. Socio-demographic data.

\begin{tabular}{|c|c|c|c|c|c|c|}
\hline Variables & & Total sample $(\mathrm{N}=34)$ & $\operatorname{VLOSLP}(n=17)$ & $\operatorname{EOS}(n=17)$ & T-test & Chi-square \\
\hline Gender (Female/Male) & & $24 / 10$ & $13 / 4$ & $11 / 6$ & - & 0.452 \\
\hline $\begin{array}{l}\text { Age at evaluation } \\
\text { (years) }\end{array}$ & & $\begin{array}{l}70.9(8.8) \\
\text { Range: } 50-84\end{array}$ & $76.3(4.2)$ & $65.5(9.1)$ & $<0.001^{*}$ & \\
\hline $\begin{array}{l}\text { Age at first symptoms } \\
\text { (years) }\end{array}$ & & $\begin{array}{l}50.9(22.9) \\
\text { Range: } 17-84\end{array}$ & $71.2(5.6)$ & $27.9(7.4)$ & $<0.001^{*}$ & - \\
\hline Age at diagnosis (years) & & $\begin{array}{l}52.8(22.8) \\
\text { Range: } 17-81\end{array}$ & $73.1(5.3)$ & $29.9(7.3)$ & $<0.001^{*}$ & - \\
\hline $\begin{array}{l}\text { Remission index } \\
{ }^{1} \text { (years) }\end{array}$ & & & $2.8(3.5)$ & $5.1(5.9)$ & 0.176 & - \\
\hline Disease duration (years) & & $19.9(17.1)$ & $5.3(5.2)$ & $36.4(8.1)$ & $<0.001^{*}$ & - \\
\hline Diagnosis & $\begin{array}{l}\text { SZ: } \\
\text { Szophreniform dis.: } \\
\text { Delusional dis.: } \\
\text { NS psychotic dis.: } \\
\text { Paraphrenia: }\end{array}$ & $\begin{array}{l}17 \\
2 \\
6 \\
7 \\
2\end{array}$ & $\begin{array}{l}2 \\
6 \\
7 \\
2\end{array}$ & 17 & - & $<0.001^{*}$ \\
\hline Education (years) & & $\begin{array}{l}9.88(4.15) \\
\text { Range: } 4-21\end{array}$ & $7.47(2.09)$ & $12.29(4.33)$ & $<0.001^{*}$ & - \\
\hline Civil status & $\begin{array}{l}\text { Single: } \\
\text { Married: } \\
\text { Divorced: } \\
\text { Widowed: }\end{array}$ & $\begin{array}{l}14 \\
7 \\
6 \\
7\end{array}$ & $\begin{array}{l}3 \\
5 \\
2 \\
7\end{array}$ & $\begin{array}{l}11 \\
2 \\
4 \\
0\end{array}$ & - & $0.004^{*}$ \\
\hline Number of children & & $\begin{array}{l}1.76(2.22) \\
\text { Range: } 0-7\end{array}$ & $2.94(2.54)$ & $0.59(0.87)$ & $0.002^{*}$ & - \\
\hline
\end{tabular}

${ }^{1}$ Number of years between last episode and evaluation; Legend: VLOSLP: Very Late-Onset Schizophrenia-Like Psychosis; EOS: Early-Onset Schizophrenia; SZ: Schizophrenia; Szophreniform dis.: Schizophreniform disorder; Delusional dis.: Delusional disorder; NS psychotic dis.: Non-specific psychotic disorder. ${ }^{*} p<0.05$.

Table 2. Medical data from medical records.

\begin{tabular}{|c|c|c|c|c|c|}
\hline Variables & $\begin{array}{l}\text { Total sample } \\
(\mathrm{N}=34)\end{array}$ & $\begin{array}{l}\text { VLOSLP } \\
(\mathrm{n}=17)\end{array}$ & $\operatorname{EOS}(n=16)$ & Chi-square & $\begin{array}{l}\text { Fisher exact } \\
\text { test }\end{array}$ \\
\hline \multicolumn{6}{|l|}{ Positive family history } \\
\hline Schizophrenia & $10 / 30$ & $2 / 16$ & $8 / 14$ & 0.010 & 0.019 \\
\hline Psychiatric disorders & $18 / 29$ & $7 / 16$ & $11 / 13$ & 0.024 & 0.052 \\
\hline Dementia & $7 / 31$ & $5 / 16$ & $2 / 15$ & 0.233 & 0.394 \\
\hline \multicolumn{6}{|l|}{ Current medication } \\
\hline Typical neuroleptics & $12 / 34$ & $2 / 17$ & $10 / 16$ & 0.004 & $0.010^{*}$ \\
\hline Atypical neuroleptics & $30 / 34$ & $16 / 17$ & $14 / 16$ & 0.287 & 0.601 \\
\hline Benzodiazepines & $24 / 33$ & $9 / 16$ & $15 / 16$ & 0.039 & 0.057 \\
\hline Antidepressants & $14 / 34$ & $8 / 17$ & $6 / 16$ & 0.486 & 0.728 \\
\hline Mood stabilizers & $3 / 34$ & $1 / 17$ & $2 / 16$ & 0.545 & 1.000 \\
\hline Anti-parkinsonian agents & $9 / 34$ & $1 / 17$ & $8 / 16$ & 0.007 & 0.017 \\
\hline Nootropics & $0 / 34$ & $0 / 17$ & $0 / 16$ & - & - \\
\hline \multicolumn{6}{|l|}{ Medical condition } \\
\hline High blood pressure & $18 / 33$ & $12 / 16$ & $6 / 16$ & 0.022 & 0.037 \\
\hline Diabetes & $10 / 33$ & $4 / 16$ & $6 / 16$ & 0.520 & 0.708 \\
\hline Dyslipidemia/hypercholesterolemia & $15 / 33$ & $7 / 16$ & $8 / 16$ & 0.849 & 1.000 \\
\hline Cardiac condition & $13 / 34$ & $7 / 17$ & $6 / 16$ & 0.724 & 1.000 \\
\hline Smoking & $6 / 34$ & $3 / 17$ & $3 / 16$ & 1.000 & 1.000 \\
\hline Obesity & $9 / 29$ & $5 / 16$ & $4 / 13$ & 0.978 & 1.000 \\
\hline Hypothyroidia & $8 / 33$ & $3 / 16$ & $5 / 16$ & 0.475 & 0.688 \\
\hline
\end{tabular}




\section{Continued}

\begin{tabular}{|c|c|c|c|c|c|}
\hline \multicolumn{6}{|l|}{ CT-Scan results } \\
\hline Abnormalities at CT-Scan & $13 / 22$ & $11 / 16$ & $2 / 6$ & 0.132 & 0.178 \\
\hline \multirow{2}{*}{\multicolumn{6}{|c|}{ Positive personality trait/disorder }} \\
\hline & & & & & \\
\hline - Paranoid & 2 & 2 & 0 & & \\
\hline - Schizotypic & 2 & 0 & 2 & & \\
\hline $\begin{array}{l}\text { - Passive-dependant } \\
\text { - Obsessive }\end{array}$ & 3 & 2 & 1 & & \\
\hline - Mixte & 3 & 2 & 1 & & \\
\hline & 3 & 1 & 2 & & \\
\hline Current anxiety symptoms & $5 / 34$ & $4 / 17$ & $1 / 16$ & 0.146 & 0.335 \\
\hline Past anxiety symptoms & $27 / 32$ & $13 / 17$ & $14 / 15$ & 0.190 & 0.338 \\
\hline Current depressive symptoms & $2 / 34$ & $2 / 17$ & $0 / 16$ & 0.145 & 0.485 \\
\hline Past depressive symptoms & $22 / 32$ & $11 / 17$ & $11 / 15$ & 0.599 & 0.712 \\
\hline
\end{tabular}

Legend: VLOSLP: Very Late-Onset Schizophrenia-Like Psychosis; EOS: Early-Onset Schizophrenia; Note: Access to medical files for 17 VLOSLP and 16 EOS. ${ }^{*} p<0.05$.

Table 3. General psychiatric profile.

\begin{tabular}{|c|c|c|c|c|c|c|}
\hline & & & $\begin{array}{l}\operatorname{VLOSLP}(n=17) \\
\text { Mean }(\text { SD) }\end{array}$ & $\begin{array}{c}\text { EOS }(n=17) \\
\text { Mean (SD) }\end{array}$ & Effect size $(d)$ & T-test $(p)$ \\
\hline \multirow{8}{*}{ Current condition } & \multirow{4}{*}{ SAPS } & Number of hallucinations (/7) & $0.75(1.18)$ & $0.82(0.95)$ & 0.07 & 0.845 \\
\hline & & Number of delusions $(/ 20)$ & $1.06(1.39)$ & $2.94(3.47)$ & 0.77 & 0.059 \\
\hline & & $\begin{array}{l}\text { Number of behavioral } \\
\text { disturbances }(/ 4)\end{array}$ & $0.19(0.54)$ & $0.59(0.71)$ & 0.64 & 0.078 \\
\hline & & $\begin{array}{l}\text { Number of formal thought } \\
\text { disorders }(/ 8)\end{array}$ & $0.75(1.57)$ & $0.47(0.94)$ & 0.22 & 0.537 \\
\hline & \multirow{4}{*}{ SANS } & $\begin{array}{l}\text { Number of affective poverty } \\
\text { symptoms }(/ 7)\end{array}$ & $1.56(1.83)$ & $2.76(2.56)$ & 0.55 & 0.133 \\
\hline & & $\begin{array}{l}\text { Number of alogia symptoms } \\
(/ 5)\end{array}$ & $0.88(1.59)$ & $1.06(1.35)$ & 0.12 & 0.721 \\
\hline & & $\begin{array}{l}\text { Number of apathy symptoms } \\
(/ 3)\end{array}$ & $1.19(1.17)$ & $1.00(1.00)$ & 0.18 & 0.623 \\
\hline & & $\begin{array}{l}\text { Number of anhedonia } \\
\text { symptoms }(/ 4)\end{array}$ & $2.19(1.52)$ & $2.76(1.39)$ & 0.39 & 0.263 \\
\hline \multirow{8}{*}{$\begin{array}{l}\text { At onset/Past } \\
\text { condition }\end{array}$} & \multirow{4}{*}{ SAPS } & Number of hallucinations (/7) & $2.06(1.52)$ & $3.94(1.44)$ & 1.27 & $0.001^{*}$ \\
\hline & & Number of delusions $(/ 20)$ & $2.65(1.62)$ & $7.06(3.13)$ & 1.86 & $<0.001^{*}$ \\
\hline & & $\begin{array}{l}\text { Number of behavioral } \\
\text { disturbances }(/ 4)\end{array}$ & $1.47(0.94)$ & $2.47(0.87)$ & 1.11 & $0.003^{*}$ \\
\hline & & $\begin{array}{l}\text { Number of formal thought } \\
\text { disorders }(/ 8)\end{array}$ & $1.53(1.97)$ & $2.43(2.28)$ & 0.42 & 0.248 \\
\hline & \multirow{4}{*}{ SANS } & $\begin{array}{l}\text { Number of affective poverty } \\
\text { symptoms }(/ 7)\end{array}$ & $1.24(1.89)$ & $2.00(1.63)$ & 0.43 & 0.224 \\
\hline & & $\begin{array}{l}\text { Number of alogia symptoms } \\
(/ 5)\end{array}$ & $0.76(1.15)$ & $1.21(1.25)$ & 0.38 & 0.306 \\
\hline & & $\begin{array}{l}\text { Number of apathy symptoms } \\
(/ 3)\end{array}$ & $1.24(1.20)$ & $2.18(0.64)$ & 1.02 & $0.009^{*}$ \\
\hline & & $\begin{array}{l}\text { Number of anhedonia } \\
\text { symptoms }(/ 4)\end{array}$ & $2.94(0.66)$ & $3.65(0.61)$ & 1.12 & $0.003^{*}$ \\
\hline
\end{tabular}

Legend: SAPS: Scale for the Assessment of Positive Symptoms; SANS: Scale for the Assessment of Negative Symptoms; VLOSLP: Very Late-Onset Schizophrenia-Like Psychosis; EOS: Early-Onset Schizophrenia. $p<0.05$. 
Table 4. Positive symptoms.

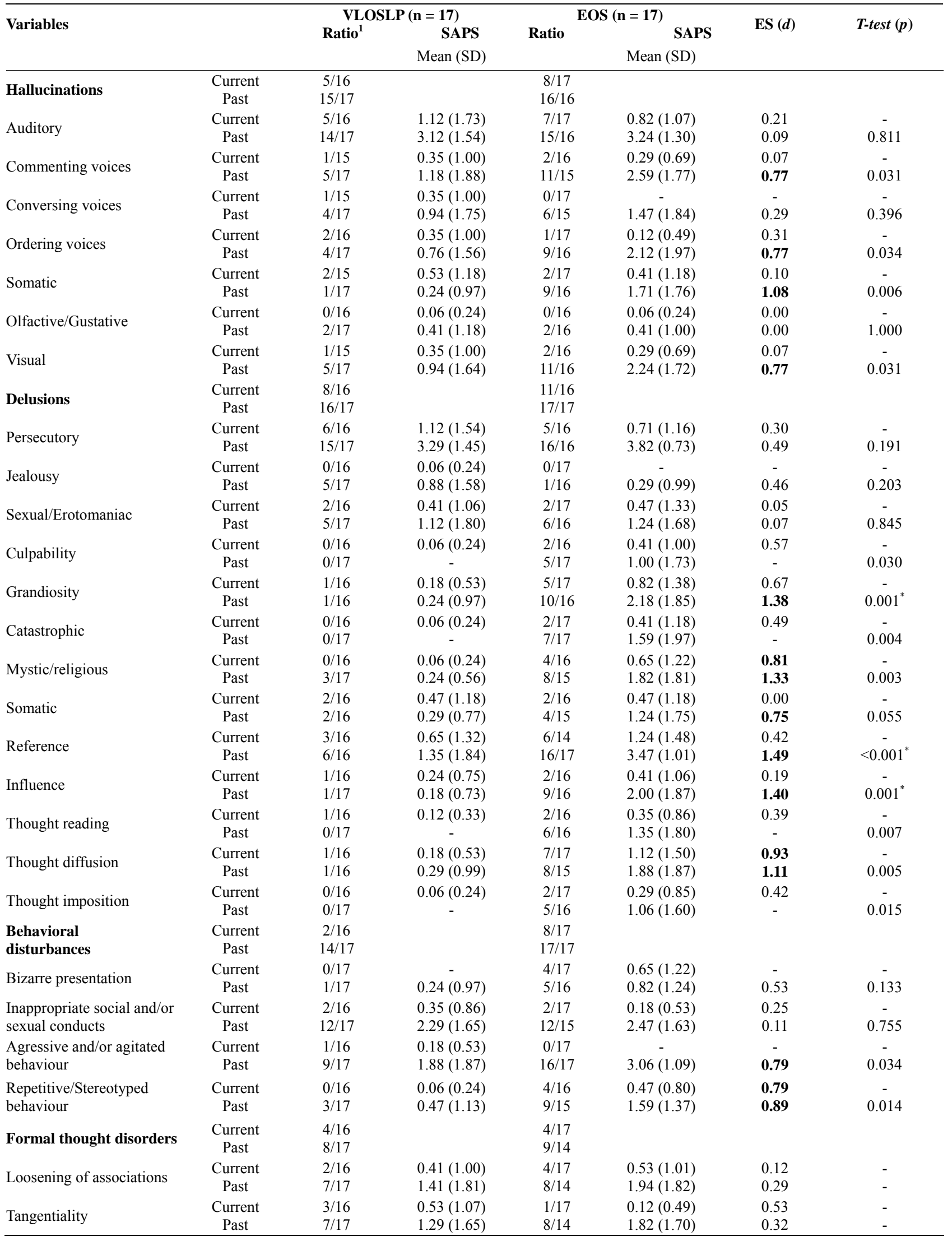




\section{Continued}

\begin{tabular}{|c|c|c|c|c|c|c|c|}
\hline Incoherence & $\begin{array}{c}\text { Current } \\
\text { Past }\end{array}$ & $\begin{array}{l}1 / 16 \\
1 / 17\end{array}$ & $\begin{array}{l}0.18(0.53) \\
0.18(0.73)\end{array}$ & $\begin{array}{l}0 / 17 \\
2 / 14\end{array}$ & $0.53(1.07)$ & $\overline{-}$ & $\begin{array}{l}- \\
-\end{array}$ \\
\hline Illogical speech & $\begin{array}{c}\text { Current } \\
\text { Past }\end{array}$ & $\begin{array}{l}1 / 16 \\
2 / 17\end{array}$ & $\begin{array}{l}0.12(0.33) \\
0.29(0.85)\end{array}$ & $\begin{array}{l}0 / 17 \\
3 / 14\end{array}$ & $0.88(1.54)$ & 0.49 & $\begin{array}{l}- \\
-\end{array}$ \\
\hline Circumstantial speech & $\begin{array}{c}\text { Current } \\
\text { Past }\end{array}$ & $\begin{array}{l}2 / 16 \\
5 / 17\end{array}$ & $\begin{array}{l}0.47(1.18) \\
0.88(1.45)\end{array}$ & $\begin{array}{l}3 / 17 \\
7 / 14\end{array}$ & $\begin{array}{l}0.47(1.07) \\
1.65(1.73)\end{array}$ & $\begin{array}{l}0.00 \\
0.48\end{array}$ & $\begin{array}{l}- \\
-\end{array}$ \\
\hline Logorrhea & $\begin{array}{c}\text { Current } \\
\text { Past }\end{array}$ & $\begin{array}{l}1 / 16 \\
2 / 17\end{array}$ & $\begin{array}{l}0.24(0.75) \\
0.35(1.00)\end{array}$ & $\begin{array}{l}0 / 17 \\
4 / 14\end{array}$ & $\frac{-}{0.82(1.24)}$ & $-\overline{42}$ & - \\
\hline
\end{tabular}

${ }^{1}$ Ratio refers to the proportion of patients presenting this symptom. Legends: VLOSLP: Very Late-Onset Schizophrenia-Like Psychosis; EOS: Early-Onset Schizophrenia; ES = Effect Size; $\mathrm{SD}=$ Standard Deviation. ${ }^{*} p<0.001$.

Table 5. Negative symptoms.

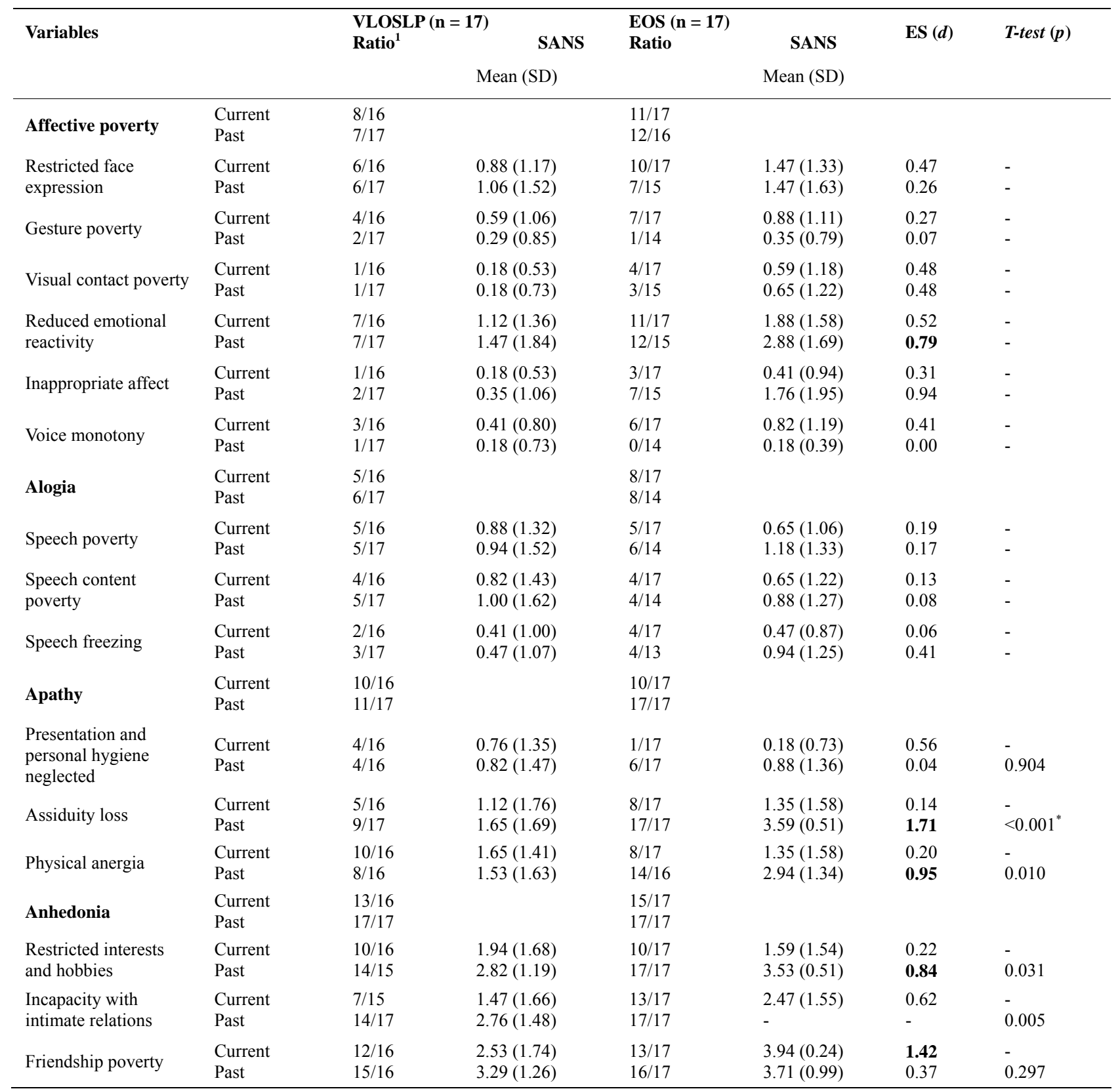

${ }^{1}$ Ratio refers to the proportion of patients presenting this symptom. Legends: VLOSLP: Very Late-Onset Schizophrenia-Like Psychosis; EOS: Early-Onset Schizophrenia; $\mathrm{ES}=$ Effect Size; $\mathrm{SD}=$ Standard Deviation. ${ }^{*} p<0.001$. 
0.2 (small effect size), $d=0.5$ (medium effect size); $d=$ 0.8 (large effect size).

\section{RESULTS}

Of the 60 patients (VLOSLP: $\mathrm{n}=33$; EOS: $\mathrm{n}=27$ ) referred for recruitment between May 2005 and August 2008, 19 refused to participate, 5 were considered non eligible following detailed investigations [cerebral tumour $(\mathrm{n}=1)$; bipolar disorder $(\mathrm{n}=1)$; psychopathic personality with paraphilia $(\mathrm{n}=1)$; impossibility to determine the onset of first symptoms $(\mathrm{n}=1)$; palliative stage $(\mathrm{n}=1)$ ], and 2 were not reachable, resulting in a final sample of 17 VLOSLP and 17 EOS.

Table 1 presents the socio-demographic data. VLOSLP had significantly more children than EOS. A matching procedure for age and education was not possible, resulting in significant differences between the groups, with VLOSLP being significantly older and less educated than elderly EOS. A visual inspection of Table 1 also reveals that both groups included more women than men, that EOS had longer disease duration than VLOSLP (which is linked to the diagnoses), and that more VLOSLP were married/widowed than EOS.

Table 2 presents the medical data. Patients with EOS took significantly more typical antipsychotics than patients with VLOSLP. A visual inspection of the results demonstrates that $84.6 \%$ of EOS had psychiatric disorders in their family compared to $43.8 \%$ in the VLOSLP. Both groups presented with vascular risk factors, and $69 \%$ of the VLOSLP for whom neuroimaging data were available at follow-up presented abnormalities, mostly vascular. Only 6/17 EOS had CT-scans and abnormal findings were reported in $33 \%$ of these patients (see Girard et al. [39], for further details and dosages of medications). Few active symptoms of depression and/or anxiety were present in a small number of patients at the current evaluation (follow-up) whereas most patients suffered from significant anxious and depressive symptoms in the past.

Tables 3-5 illustrate the patients' symptomatic profiles. Regarding positive symptoms at onset of disease/in the past, EOS presented significantly more hallucinations, delusions, and behavioural disturbances than VLOSLP per the SAPS assessment. Reference and influence delusions, and grandiosity were especially more common in EOS than in VLOSLP at the time (Table 4). Auditory hallucinations, persecutory delusions and social/sexual inadequate conducts were present in $\geq 75 \%$ of patients at onset of disorders, regardless of the group, but EOS had more commenting and ordering voices, mystic/religious and thought diffusion delusions than VLOSLP $(d \geq 0.8$; large effect size). In addition, EOS had more aggressive/ agitated and repetitive/stereotyped behaviours than VLO-
SLP ( $d \geq 0.8$; large effect size).

Data regarding the current profile of positive symptoms showed that patients were mostly in remission with no symptom being actually endorsed by a majority of patients ( $\geq 75 \%)$ in both groups. However, EOS had more residual symptoms of mystic/religious and thought diffusion delusions as well as more repetitive/stereotyped behaviours than VLOSLP $(d \geq 0.8)$.

Regarding the negative symptoms as measured by the SANS, EOS patients presented significantly more apathy and anhedonia than VLOSLP patients but only at the onset of the psychotic disorder (in the past). The detailed analysis of the negative symptoms (Table 5) revealed that only assiduity loss was significantly more present at onset of the disorder (past) in EOS than in VLOSLP. Symptoms of apathy and anhedonia were relatively common in the current (follow-up) condition of most patients regardless of the group.

\section{DISCUSSION}

This study compared the positive and negative symptoms at onset of the psychotic disorder/past condition and at current (follow-up) evaluation of patients with VLOSLP versus those with EOS. Different past and current symptomatologies between the two groups were described, with an overall more severe psychotic disorder in EOS than in VLOSLP.

We had hypothesized that VLOSLP patients would present with less severe past (at onset of the disorder) positive symptoms than EOS. The results confirmed this hypothesis.

EOS presented at onset/in the past more types of hallucinations, delusions, and behavior disturbances than VLOSLP. Regarding the delusion profile, EOS patients presented more grandiosity, influence and reference delusions than VLOSLP. These symptoms are common in schizophrenia. Presence of auditory hallucinations and persecutory delusions as principal symptoms of the two groups is compatible with the observations of prior reports on VLOSLP [24,25,35]. Nonetheless, the history of more florid delusions in EOS compared with VLOSLP cannot be ascertained without doubt given that the period considered for the coding of past symptoms referred to a longer interval of time in EOS (more than 36.4 years) than in VLOSLP (mean of 5.3 years). However, the facts that VLOSLP had a better premorbid social functioning (more marriages and children) and took less typical antipsychotics than EOS seemingly support the more severe profile of EOS. Typical neuroleptics are mostly prescribed in treatment-resistant cases. Taken altogether, these data partly corroborate the nosology and the hypothesis of milder schizophrenia symptoms in VLOSLP than in EOS as proposed by the International Late-onset 
Schizophrenia Group [5], and more recent reports [14, 26].

The results of this article are inconsistent with previous observations of more formal thought disorders in EOS than in VLOSLP [5]. This could be explained by a sample bias as the present community volunteer EOS were perhaps less affected by the pathology than patients in other studies, and conversely, the VLOSLP or a proportion of VLOSLP were probably more cognitively impaired at follow-up. Indeed, $80 \%-93.3 \%$ of the VLOSLP patients (depending on the psychiatrist or neuropsychologist who made the diagnosis see [39] for the method of consensus dementia/cognitive impairment diagnosis at follow-up) had cognitive deficits at followup and $20 \%$ evolved towards dementia over a mean period of 2.4 (3.1 SD) years after the onset of psychosis [39]. In addition, the ILOS Group proposed that visual hallucinations would be more prevalent in VLOSLP than in EOS [5]. The present study invalidated this hypothesis.

Regarding the past negative symptoms, we had hypothezied that VLOSLP patients would present with some negative symptoms, but of less severity than the negative symptoms of EOS patients. In accordance with this hypothesis, the results showed that EOS had presented more apathy and anhedonia symptoms in the past than VLOSLP, and especially more assiduity loss. This difference in the clinical profile between VLOSLP and EOS could reflect a more severe negative pathology in the elderly EOS than previously suggested by some authors, especially in women [28]. This could also be the result of a bias regarding different disease duration in the two groups.

Data regarding current symptoms suggests some remission and/or symptom improvement in both groups. Good response to atypical neuroleptics in VLOSLP is consistent with previous data $[20,26,34,35]$. Indeed few positive symptoms were actually endorsed in the current condition (follow-up) by the patients, with delusions being the most present in 50\% of the VLOSLP and 69\% of the EOS. Persecutory delusions were the most prominent residual symptom in VLOSLP while elderly EOS presented various types of delusions. This observation is in accordance with a more florid versus more systematized/restricted delusions described, respectively, in EOS and VLOSLP $[5,14,26]$. The current low prevalence of positive symptoms in the groups might have produced a floor effect reducing the possibility to observe other between-group differences.

The current negative profile highlights residual symptoms of affective poverty, apathy and anhedonia in both groups which are consistent with previous reports in VLOSLP [14,25]. These residual symptoms might also be explained by a lesser efficacy of neuroleptics to con- trol negative symptoms [41]. It is also possible that some symptoms such as reduced facial expression and energy might be extrapyramidal side effects of the medication rather than intrinsic negative symptoms [42]. However, this is less likely given that extrapyramidal side effects are more common in typical than in atypical neuroleptics, and that most VLOSLP (16/17) received atypical neuroleptics at an inferior percentage of maximum dose than EOS $(22.8 \%$ versus $50.2 \%$ for, respectively, VLOSLP and EOS [39]).

In terms of demographics, we had hypothesized that VLOSLP patients would be predominantly female and would be less educated than EOS. The results confirmed our hypotheses. There were more women than men in VLOSLP and EOS. This finding is partly consistent with the reports of female preponderance in VLOSLP $[1,5$, 25]. The volunteer participation of patients in the present study possibly explains the discrepancies; women are usually more likely to participate than men [43]. VLOSLP had lower education than EOS, which is consistent with previous data [14], and in contradiction with others [26]. In the present study, the education difference might be cultural as high school was not legally mandatory up until the sixties in the province of Quebec.

The two patient groups had at follow-up overall comparable profiles for vascular risk factors (VRF), which is surprising given that VLOSLP were older than EOS, and because VRF typically increase at midlife [44]. Yet this type of results was previously reported [45]. However, in the present study, cerebral lesions, generally of vascular nature, were found on CT-scans in $68.8 \%$ of VLOSLP at current (follow-up) evaluation only. On the contrary, the EOS patients were not suspected to present abnormalities since the majority of these patients were not administered neuroimaging exams by their treating physicians. Only the third of the EOS with CT-scans (2/6) presented abnormal results at current evaluation. These findings suggest the development of greater cerebrovascular vulnerability in VLOSLP than in EOS, thus corroborating neurodegenerative/neurovascular reports of previous studies $[7,26,36,38]$.

Some methodological limitations must be mentioned. Despite a multicentre recruitment, the relatively low prevalence of VLOSLP patients previously reported in the French-speaking population of Quebec City (0.7\%) [25] compared to LOS, and the high rate of refusal (nearly $33 \%$ ) restricted the sample size. This possibly limited statistical power and sample representativeness. In addition, the team voluntarily adopted a conservative scoring approach i.e. symptoms denied by a patient and not reported in the medical file or by a relative were scored as absent. This choice might have masked some symptoms. The impossibility to interview a relative in $47 \%$ of the patients did not permit to bypass the lack of insight 
commonly mentioned in schizophrenia [46] and in late paraphrenia [47]; thus some symptoms might have been missed.

The SAPS/SANS were completed by a single rater, which ensured the consistency of ratings, but could have introduced a bias in scoring if the rater had preconceptions. The absence of inter-rater procedure must also be mentioned since there was variability in the details of medical records filled by different physicians at onset of the disorders. This might be explained by the fact that patients were recruited in several settings. This shortcoming is characteristic of historical cohorts. Furthermore, negative symptoms could have been difficult to distinguish from the confounding effects of depression, medications, institutionalization, poverty, etc. [48].

Finally, inconsistency regarding the onset of disease and group composition must be considered. Indeed, the onset of symptoms was preferentially defined as the moment symptoms were first noticed by the patient/family member. When this information was unavailable, onset was defined as the time of diagnosis. However, this method is less reliable; first signs of psychosis may arise many years before the diagnosis. This may have resulted by the inclusion in the VLOSLP group of some patients presenting first psychotic symptoms before the age of 40 years old, although the mean old age at diagnosis (mean = $73.1 \pm 5.3$ years) makes this hypothesis unlikely. Alternatively, it is possible that patients who presented cerebral abnormalities at follow-up were in fact suffering from some prior cerebral dysfunction that was unrecognized at the onset of psychotic symptoms or masked by the presence of psychotic symptoms.

Despite these limitations, this study provided important data on the current and past symptomatic presentation of VLOSLP in a French-speaking population living in the community.

\section{ACKNOWLEDGEMENTS}

The authors wish to thank Drs. Robert Noiseux, François Primeau, Nicole Robert, Michel Dugas, François Rousseau, Nadine Gagnon, Evelyn Keller and Patrick Bernier for kindly referring the patients. This work was supported by doctoral awards (C.G.) from Réseau Québécois de Recherche sur le Vieillissement, Fonds de la Recherche en Santé du Québec, and Fondation de l'Université Laval (Bourse Hydro Québec), and by a 2005 NARSAD Young Investigator Award (M.S). Parts of this article were presented at the $2^{\text {nd }}$ Schizophrenia International Research Society Conference, Firenze, Italy, April 10-14 $4^{\text {th }}, 2010$.

\section{REFERENCES}

[1] Meesters, P.D., et al. (2012) Schizophrenia spectrum disorders in later life: Prevalence and distribution of age at onset and sex in a Dutch catchment area. American Journal of Geriatric Psychiatry, 20, 18-28.
doi:10.1097/JGP.0b013e3182011b7f

[2] Mitford, E., Reay, R., McCabe, K., Paxton, R. and Turkington, D. (2010) Ageism in first episode psychosis. International Journal of Geriatric Psychiatry, 25, 11121118. doi:10.1002/gps.2437

[3] Reeves, R.R. and Brister, J.C. (2008) Psychosis in Late life: Emerging issues. Journal of Psychosocial Nursing, 46, 45-52.

[4] Bartels, S.J., Clark, R.E., Peacock, W.J., Dums, A.R. and Pratt, S.I. (2003) Medicare and medicaid costs for schizophrenia patients by age cohort compared with costs for depression, dementia, and medically ill patients. American Journal of Geriatric Psychiatry, 11, 648-657.

[5] Howard, R., Rabins, P.V., Seeman, M.V., Jeste, D.V. and the International Late-Onset Schizophrenia Group (2000) Late-onset schizophrenia and very-late-onset schizophrenia-like psychosis: An international consensus. American Journal of Psychiatry, 157, 172-178. doi:10.1176/appi.ajp.157.2.172

[6] Pearman, A. and Batra, A. (2012) Late-onset schizophrenia: A review for clinicians. Clinical Gerontologist, 35, 126-147. doi:10.1080/07317115.2011.642943

[7] Lagodka, A. and Robert, P. (2009) Is late-onset schizophrenia related to neurodegenerative process? A review of the literature. L'Encéphale, 35, 386-393.

doi:10.1016/j.encep.2008.06.008

[8] Howard, R., Castle, D., Wessely, S. and Murray, R.M. (1993) A comparative study of 470 cases of early- and late-onset schizophrenia. British Journal of Psychiatry, 163, 352-357. doi:10.1192/bjp.163.3.352

[9] Jeste, D.V., Harris, M.J., Krull, A., Kuck, J., McAdams, L.A. and Heaton, R. (1995) Clinical and neuropsychological characteristics of patients with late-onset schizophrenia. American Journal of Psychiatry, 152, 722-730.

[10] Palmer, B.W., Bondi, M.W., Twamley, E.W., Thal, L., Golshan, S. and Jeste, D.V. (2003) Are late-onset schizophrenia spectrum disorders neurodegenerative conditions? Annual rates of change on two measures. Journal of Neuropsychiatry and Clinical Neurosciences, 15, 4552. doi:10.1176/appi.neuropsych.15.1.45

[11] Sato, T., Bottlender, R., Schröter, A. and Moller, H.J. (2004) Psychopathology of early-onset versus late-onset schizophrenia revisited: An observation of 473 neurolepticnaïve patients before and after first-admission treatments. Schizophrenia Research, 67, 175-183. doi:10.1016/S0920-9964(03)00015-X

[12] Huang, C. and Zhang, Y. (2009) Clinical differences between late-onset and early-onset chronically hospitalized elderly schizophrenic patients in Taiwan. International Journal of Geriatric Psychiatry, 24, 1166-1172. doi:10.1002/gps.2241

[13] Köhler, S., van Os, J., de Graaf, R., Vollebergh, W., Verhey, F. and Krabbendam, L. (2007) Psychosis risk as a function of age at onset: A comparison between earlyand late-onset psychosis in a general population sample. Social Psychiatry and Psychiatric Epidemiology, 42, 288294. doi:10.1007/s00127-007-0171-6

[14] Köhler, S., et al. (2009) Evidence that better outcome of 
psychosis in women is reversed with increasing age at onset: A population-based 5-year follow-up study. Schizophrenia Research, 113, 226-232. doi:10.1016/j.schres.2009.05.017

[15] Vahia, I.V., Palmer, B.W., Depp, C., Fellows, I., Golshan, S., Kraemer, H.C. and Jeste, D.V. (2010) Is late-onset schizophrenia a subtype of schizophrenia? Acta Psychiatrica Scandinavia, 122, 414-426. doi:10.1111/j.1600-0447.2010.01552.x

[16] Riecher-Rössler, A., Häfner, H., Häfner-Ranabauer, W., Löffler, W. and Reinhard, I. (2003) Late-onset schizophrenia versus paranoid psychoses: A valid diagnostic Distinction? American Journal of Geriatric Psychiatry, 11, 595-604.

[17] Brunelle, S., Cole, M.G. and Elie, M. (2011) Risk factors for late-onset psychoses: A systematic review of cohort studies. International Journal of Geriatric Psychiatry, 27, 240-252. doi:10.1002/gps.2702

[18] Hassett, A. (1999) A descriptive study of first presentation psychosis in old age. Australian and New Zealand Journal of Psychiatry, 33, 814-824. doi:10.1046/j.1440-1614.1999.00651.x

[19] Quin, R.C., Clare, L., Ryan, P. and Jackson, M. (2009) Not of this world: The subjective experience of late-onset psychosis. Aging and Mental Health, 13, 779-787. doi:10.1080/13607860903046453

[20] Reeves, S., Stewart, R. and Howard, R. (2002) Service contact and psychopathology in very-late-onset schizophrenia-like psychosis: The effects of gender and ethnicity. International Journal of Geriatric Psychiatry, 17, 473- 479. doi:10.1002/gps.614

[21] Reeves, S., Hudson, S., Fletcher, H., Sauer, J., Stewart, R. and Howard, R. (2003) Are black Caribbean patients likely to receive an incorrect diagnosis of very-late-onset schizophrenia-like psychosis than their white British counterparts? American Journal of Geriatric Psychiatry, 11, 674-677.

[22] Romero-Rubiales, F., Reeves, S. and Howard, R. (2004) Have risk factors for very-late-onset schizophrenia-like psychosis changed in the last 40 years? International Journal of Geriatric Psychiatry, 19, 803-807. doi:10.1002/gps.1152

[23] Mitter, P., Reeves, S., Romero-Rubiales, F., Bell, P., Stewart, R. and Howard, R. (2005) Migrant status, age, gender and social isolation in very late-onset schizophrenialike psychosis. International Journal of Geriatric Psychiatry, 20, 1046-1051. doi:10.1002/gps.1396

[24] Alici-Evcimen, Y., Ertan, T. and Eker, E. (2003) Case series with late-onset psychosis hospitalized in geriatric psychiatry unit in Turkey: Experience in 9 years. International Psychogeriatrics, 15, 69-72. doi:10.1017/S1041610203008767

[25] Girard, C. and Simard, M. (2008) Clinical characterization of late- and very-late-onset first psychotic episode in psychiatric inpatients. American Journal of Geriatric Psychiatry, 16, 478-487. doi:10.1097/JGP.0b013e31816c7b3c

[26] Barak, Y., Aizenberg, D., Mirecki, I., Mazeh, D. and Achiron, A. (2002) Very late-onset schizophrenia-like psy- chosis: Clinical and imaging characteristics in comparison with elderly patients with schizophrenia. Journal of Nervous Mental Disease, 190, 733-736. doi:10.1097/00005053-200211000-00002

[27] Arbus, C., Clement, J.-P., Bougerol, T., Fremont, P., Lancrenon, S. and Camus, V. (2012) Health management of older persons with chronically medicated disorders: The results of a survey in France. International Psychogeriatrics, 24, 496-502. doi:10.1017/S1041610211001487

[28] Häfner, H., Hambrecht, M., Löffler, W., Munk-Jorgensen, P. and Riecher-Rössler, A. (1998) Is schizophrenia a disorder of all ages? A comparison of first episodes and early course across the life-cycle. Psychological Medicine, 28, 351-365. doi:10.1017/S0033291797006399

[29] Mazeh, D., Zemishani, C., Aizenberg, D. and Barak, Y. (2005) Patients with very-late-onset schizophrenia-like psychosis: A follow-up study. American Journal of Geriatric Psychiatry, 13, 417-419.

[30] Howard, R.J., et al. (1997) A controlled family study of late-onset non-affective psychosis (late paraphrenia). British Journal of Psychiatry, 170, 511-514. doi:10.1192/bjp.170.6.511

[31] Bentall, R.P., et al. (2009) The cognitive and affective structure of paranoid delusions. Archives of General Psychiatry, 66, 236-247. doi:10.1001/archgenpsychiatry.2009.1

[32] Andreasen, N.C. (1984) Scale for the assessment of positive symptoms (SAPS). University of Iowa, Iowa City.

[33] Andreasen, N.C. (1983) Scale for the assessment of negative symptoms (SANS) University of Iowa, Iowa City.

[34] Psarros, C., Theleritis, C.G., Paparrigopoulos, T.J., Politis, A.M. and Papadimitriou, G.N. (2009) Amisulpride for the treatment of very-late-onset schizophrenia-like psychosis. International Journal of Geriatric Psychiatry, 24, 518522. doi:10.1002/gps.2146

[35] Scott, J., Greenwald, B.S., Kramer, E. and Shuwall, M. (2011) Atypical (second generation) antipsychotic treatment response in very late-onset schizophrenia-like psychosis. International Psychogeriatrics, 23, 742-748. doi:10.1017/S1041610210002188

[36] Brodaty, H., Sachdev, P., Koschera, A., Monk, D. and Cullen, B. (2003) Long-term outcome of late-onset schizophrenia: 5-year follow-up study. British Journal of Psychiatry, 183, 213-219. doi:10.1192/bjp.183.3.213

[37] Casanova, M.F., Stevens, J.R., Brown, R., Royston, C. and Bruton, C. (2002) Disentangling the pathology of schizophrenia and paraphrenia. Acta Neuropathologica, 103, 313-320. doi:10.1007/s00401-001-0468-6

[38] Tsujino, N., et al. (2011) Cerebral blood flow changes in very-late-onset schizophrenia-like psychosis with catatonia before and after successful treatment. Psychiatry and Clinical Neurosciences, 65, 600-603. doi:10.1111/j.1440-1819.2011.02257.x

[39] Girard, G., et al. (2011) Late-onset-psychosis: Cognition. International Psychogeriatrics, 23, 1301-1306. doi:10.1017/S1041610211000238

[40] Cohen, J. (1988) Statistical power analysis for the behavioral sciences. 2nd Edition, Lawrence Erlbaum Associates, 
Hillsdale.

[41] Jockers-Scherübl, M.C., Bauer, A., Godemann, F., Reischies, F.M., Selig, F. and Schlattman, P. (2005) Negative symptoms of schizophrenia are improved by the addition of paroxetine to neuroleptics: A double-blind placebo controlled study. International Clinical Psychopharmacology, 20, 27-31. doi:10.1097/00004850-200501000-00006

[42] Gareri, P., De Fazio, P., De Fazio, S., Marigliano, N., Ferreri Ibbadu, G. and Sarro, G. (2006) Adverse effects of atypical antipsychotics in the elderly: A review. Drugs and Aging, 23, 937-956. doi:10.2165/00002512-200623120-00002

[43] Lee, S., Saito, T., Takahashi, M. and Kai, I. (2008) Volunteer participation among older adults in Japan: An analysis of participation and reasons for non-participation. Archives of Gerontology and Geriatry, 47, 173-187. doi:10.1016/j.archger.2007.08.004

[44] Wiederkehr, S., Simard, M., Fortin, C. and van Reekum, R. (2008) Validity of the clinical diagnostic criteria for vascular dementia: A critical review. Part II. The Journal of Neuropsychiatry and Clinical Neurosciences, 20, 162-
177. doi:10.1176/appi.neuropsych.20.2.162

[45] Sachdev, P., Brodaty, H., Rose, N. and Cathcart, S. (1999) Schizophrenia with onset after age 50 years. 2: Neurological, neuropsychological and MRI investigation. British Journal of Psychiatry, 175, 416-421. doi:10.1192/bjp.175.5.416

[46] Ostling, S., Borjesson-Hanson, A. and Skoog, I. (2007) Psychotic symptoms and paranoid ideation in a population-based sample of 95-year-olds. American Journal of Geriatric Psychiatry, 15, 999-1004. doi:10.1097/JGP.0b013e31814622b9

[47] Almeida, O., Levy, R., Howard, R.J. and David, A.S. (1996) Insight and paranoid disorders in late life (late paraphrenia). International Journal of Geriatric Psychiatry, 11, 653-658.

doi:10.1002/(SICI)1099-1166(199607)11:7<653::AID-G PS380>3.0.CO;2-9

[48] Howard, R. (2001) Late-onset schizophrenia and very late-onset schizophrenia-like psychosis. Review in Clinical Gerontology, 11, 337-352.

doi:10.1017/S0959259801011455 